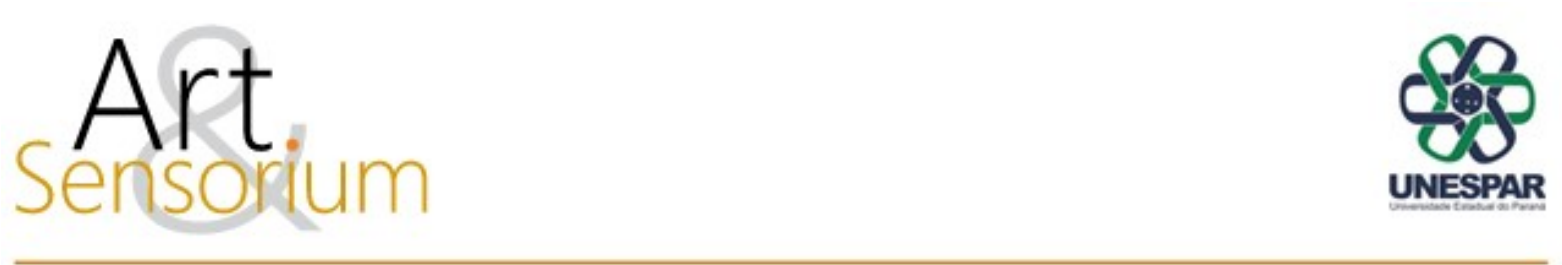

\title{
PERSISTÊNCIA DAS NATUREZAS-MORTAS NA ARTE CONTEMPORÂNEA: DIÁLOGOS COM UMA PROPOSTA EXPOSITIVA
}

DOI: $\underline{\text { https://doi.org/10.33871/23580437.2020.7.2.015-027 }}$

\author{
Milena Regina Duarte Corrêa ${ }^{1}$ \\ Antonio José dos Santos Junior ${ }^{2}$ \\ Stéfani Trindade Agostini ${ }^{3}$
}

\begin{abstract}
Resumo: Esse texto apresenta a temática da natureza-morta na arte contemporânea e sua persistência através do tempo. Como mote para essa problematização, relata uma proposta expositiva de naturezas-mortas contemporâneas que traduzem, literalmente, como as formas e os temas sobrevivem e se adaptam nos dias que correm. Tem objetivo de discutir como um gênero tradicional da história da arte ainda pode ser atualizado e potencializado de diferentes modos na arte contemporânea. A metodologia da escrita é de cunho bibliográfico, se atrelando aos conceitos propostos por Didi-Huberman (2013) no que se refere a sobrevivência das imagens. Na segunda parte do texto, comenta a proposta expositiva $O$ último que sair encoste a porta, como forma de contextualização dos conceitos propostos. Espera-se que esse estudo oportunize um diálogo contemporâneo acerca de um tema clássico e, mostre como é possível revisitar e atualizar as naturezas-mortas para que hoje se manifestem de forma contestadora e potente.
\end{abstract}

Palavras-chave: Persistência; natureza-morta; arte contemporânea; exposição.

\footnotetext{
${ }^{1}$ Doutoranda em Artes Visuais, na linha de pesquisa teórica: Arte e Transversalidade, pelo Programa de Pós-Graduação em Artes Visuais/ PPGART - Universidade Federal de Santa Maria. Mestra em Artes Visuais, linha de pesquisa teórica: Arte e Cultura, pelo mesmo programa e instituição, bolsista CAPES 2018/2019. Graduada em Artes Visuais Licenciatura Plena /UFSM. Membra do grupo de pesquisa SIGNUM/CNPq. Tem interesse nas áreas de arte contemporânea, naturezas-mortas, iconografia e estudos da imagem. Orcid: https://orcid.org/0000-0001-7962-7399. milenadc27@gmail.com

2 Mestre em Artes Visuais, linha de pesquisa Arte e Visualidade, pelo Programa de Pós-Graduação em Artes Visuais/PPGART - Universidade Federal de Santa Maria. Bolsista CAPES 2018-2020. Artista Visual - Desenho e Plástica - UFSM, com mobilidade acadêmica na Faculdade de Belas Artes da Universidade do Porto, Portugal. Integrante dos grupos de pesquisa: Arte Impressa e Ecologia/CNPq e Processos Pictóricos/CNPq. Tem interesse em investigar processos de criação na contemporaneidade. Orcid: https://orcid.org/0000-0001-5641-7663. antoniojunior_jr@hotmail.com

${ }^{3}$ Artista Visual. Mestranda em Artes Visuais, linha de pesquisa Arte e Cultura, pelo Programa de Pós-Graduação em Artes Visuais/PPGART - Universidade Federal de Santa Maria. Bacharela em Artes Visuais na mesma instituição. Membra dos grupos de pesquisa: Processos Pictóricos/ CNPq, SIGNUM/CNPq e Arte e Ecologia/CNPq. Como artistapesquisadora dedica-se a investigar a ausência materna. Orcidi: https://orcid.org/0000-0002-3039-9505. tefiago_@hotmail.com
} 


\title{
PERSISTENCE OF STILL LIFE IN CONTEMPORARY ART: DIALOGUES WITH AN EXPOSITIVE PROPOSAL
}

\begin{abstract}
This text presents the theme of still life in contemporary art and its persistence through time. As a motive for this problematization, it reports on an expository proposal of contemporary still lifes that literally translate how these forms and themes survive and adapt today. It aims to discuss how a traditional genre of art history can still be updated and enhanced in different ways in contemporary art. The writing methodology is bibliographic in nature, linked to the concepts proposed by Didi-Huberman (2013) regarding the survival of images. In the second part of the text, it comments on the expository proposal of the exhibition $O$ último que sair encoste a porta, as a way of contextualizing the proposed concepts. It is hoped that this study will provide a contemporary dialogue on a classic theme, and show how it is possible to revisit and update still lifes, so today they can manifest themselves in a challenging and potent way.
\end{abstract}

Keywords: Persistence; still life; contemporary art; exhibition.

\section{PERSISTENCIA DE NATURALEZAS MUERTAS EN EL ARTE CONTEMPORÁNEO: DIÁLOGOS CON UNA PROPUESTA EXPOSITIVA}

Resumen: Este texto presenta el tema de la naturaleza muerta el en arte contemporáneo y su persistencia en el tiempo. Como lema para esta problematización, informa sobre una propuesta expositiva de bodegones contemporáneos que traduce literalmente cómo las formas y los temas sobrevivén y se adaptan hoy. Su objetivo es discutir cómo un género tradicional de la historia del arte todavía se puede actualizar y mejorar de diferentes maneras en el arte contemporáneo. La metodología de escritura es de naturaleza bibliográfica, vinculada a los conceptos propuestos por Didi-Huberman (2013) sobre la supervivencia de las imágenes. En la segunda parte del texto comenta sobre la propuesta expositiva $O$ ultimo que sair encoste a porta, como una forma de contextualizar los conceptos propuestos. Se espera que este estudio proporcione un diálogo sobre un tema clásico y muestre cómo es posible revisar y actualizar bodegones para que hoy se manifesten de una manera desafiante y potente.

Palabras clave: Persistencia; naturaleza muerta; arte contemporáneo; exposición.

\section{Introdução}

Nesse texto é apresentado o gênero da natureza-morta como uma potência que sobrevive a passagem do tempo e a história, para se desenvolver e se atualizar com novos desdobramentos na arte contemporânea. Para elucidar essa articulação, apresenta-se uma proposta expositiva de naturezas-mortas contemporâneas, intitulada $O$ último que sair encoste a porta, com intenção de perceber como as imagens podem produzir sentido não só para os artistas dessa exposição, mas para todo o público que ela alcança.

Na primeira parte da escrita, o gênero tão recursivo da história da arte é apresentado: a naturezamorta. Sua aparição silenciosa e inferior, com objetos discretos e uma vida em suspenso, se mostrou como um motivo real para a pintura durante os séculos XVI, XVII, XVII, XIX e XX. Entretanto, só no decorrer desse tempo que ela foi conquistando seu espaço autônomo no território privilegiado de outras imagens da arte.

À vista disso, acompanhando todas as mudanças culturais e artísticas, percebe-se que, além de ter alcançado um papel importante nessa história, a natureza-morta tem se mostrado adaptável e duradoura nas produções contemporâneas. Mudando seus discursos e sua apresentação a partir de outros enfoques, ela passa a questionar e problematizar, mais do que apenas representar seu contexto histórico.

R. Inter. Interdisc. Art\&Sensorium, Curitiba, v.7, n.2, p. 015 - 027 Jul.- Dez. 2020 
Se a imagem da natureza-morta ainda aparece, mesmo depois de tanto tempo, significa que, a despeito de poder ter desaparecido, ela reviveu, persistiu e sobreviveu durante os tempos. Atravessou as limitações que, por algum motivo, faz algumas imagens desaparecerem e perderem sua força na história, para assim, apresentar-se de outra forma na arte contemporânea. E, nesse texto, pelo viés da cultura visual podemos atualiza-las para que ainda discutam e problematizem.

Diante disso, para traduzirmos de forma prática esse objetivo, na segunda parte do texto é apresentada a proposta expositiva de naturezas-mortas $O$ último que sair encoste a porta, pensada e organizada por alguns estudantes/artistas do Curso de Artes Visuais da Universidade Federal de Santa Maria - Rio Grande do Sul - Brasil, onde expõem pinturas de naturezas-mortas sob diferentes pontos de vista e técnicas, acerca de um mesmo espaço.

A exposição mostra uma deslocalização do olhar de cada artista sobre aqueles objetos que compunham um mesmo espaço. Significa que, algumas vezes, o mesmo objeto aparece na pintura de artistas diferentes, mas sua representação é singular e diz muito sobre quem o pintou. No conjunto de pinturas, percebe-se claramente alguns sintomas da história da arte que a pintura contemporânea modifica e torna mais atual e viva.

Nessa mostra, confirma-se o quanto a pintura na arte contemporânea sobrevive, mas passa a dialogar sobre questões além da arte, apresentando-se de modo mais plural e híbrido. Uma pintura que não leva em conta só a representação do objeto como ele se apresenta ao espectador, mas a vida, e a cultura daquele artista. Com isso, torna-se possível perceber a potência daquelas imagens isoladas ou em conjunto, que atravessaram fronteiras além da representação e produzem diferentes significados e posições discursivas.

\section{Naturezas-mortas ainda vivem: sua persistência na arte contemporânea}

A presença da natureza-morta na história da arte é incontestável. Entende-se por presença a condição de algo estar em determinado lugar específico; um termo que pode ser referido à assiduidade, à constância, à frequência e ao compromisso; é sinônimo de comparecimento. Estar presente significa que, apesar de determinadas condições, foi possível estar ali. A presença é também relacionada com a insistência de permanecer, de continuar ou até de voltar. Portanto, a presença da natureza-morta supõe que, mesmo podendo ter desaparecido, ela continua presente. Mais ainda, que um dia ela teve força suficiente para superar limites e se fazer presente.

Assim como todas as imagens, o gênero da natureza-morta superou algumas fronteiras para ter sua presença reconhecida na história da arte e ainda, para ter um nome e um local nessa história. Num tempo em que grandes artistas eram conhecidos por pintarem paisagens e retratos, e a representação de objetos era apenas o nível mais baixo da pintura. As comidas eram inferiores, assim como o gosto e o olfato, em detrimento do sentido da visão, que parecia muito mais interessante. Mesmo diante dessas condições, a natureza-morta desafiou os limites sistemáticos que acreditavam que os objetos inertes e silenciosos não eram dignos de atenção por não terem voz. Ela se mostrou resistente o suficiente para abdicar do que a sustentava - a figura humana- para investir em um espaço autônomo.

Depois de encontrar seu lugar, a natureza-morta é vista em grande parte dos acervos de pinturas dos anos 1500 em diante. Começando com a pintura Holandesa, as cenas caseiras e tendas de comida dos anos 1600 - época marcada por revoluções econômicas e escassez de bens alimentares. Bem como a representação das Xenias - pinturas romanas das pinturas gregas de comida, representando a hospitalidade dos anfitriões da época. E, um dos temas mais conhecidos: as Vanitas. Em latim, significa vacuidade, futilidade, vanitas vanitatium; na história da arte pode ser interpretada como vaidade e pode ser compreendida como uma insinuação à efemeridade da vida, a morte e a exaltação da vaidade.

R. Inter. Interdisc. Art\&Sensorium, Curitiba, v.7, n.2, p. 015 - 027 Jul.- Dez. 2020 
Em suma, por tratar de cenas internas e caseiras, a natureza-morta nos leva ao mais íntimo e privado nas pinturas. Objetos que pertenciam a determinadas pessoas e que retratavam seu cotidiano e suas vidas. Assim como tantas vezes escondia significados ocultos em suas composições, tratando de questões religiosas e até ilusórias, esse era seu principal papel.

Depois disso, chegando na modernidade, as coisas mudaram, assim como tudo naquele tempo. Os artistas modernos já tinham motivos para fazê-la. Fizeram de seus ateliês, composições. De seus alimentos, motivos para representar seu cotidiano, para expor seus conhecimentos sobre estrutura compositiva. A natureza-morta passa a ser um motivo para pintar e um gatilho para que os artistas demonstrassem sua técnica e conhecimento sobre cor, luz, sombra, perspectiva e textura.

Essa revisão sobre as primeiras formas de manifestação da natureza-morta no decorrer da história, auxiliam na contextualização e comparação sobre a presença e a marca dos objetos nos dias contemporâneos. Hoje, é evidente que os objetos mudaram de posição, ganharam mais atenção e passaram a comunicar sobre a cultura e o estilo de vida das pessoas; eles dizem muito sobre elas. Os bens materiais de alguém, por vezes, tem um valor tão importante quanto suas vidas. Portanto, fazer desses objetos uma forma de representar determinada coisa, de contestar, de resistir, de problematizar outras, é um dos motivos pelos quais a natureza-morta tem a sua presença marcada na arte contemporânea.

Entende-se por contemporâneo, segundo Giorgio Agamben (2013) aquele momento singular, sem limitações, regras ou estruturas lineares, e que estabelece uma relação diferente com esse e com outros tempos. A distância que o contemporâneo mantém sobre seu tempo se refere a sua necessidade de não pertencimento àquele lugar e àquelas ideias, porque ele tem necessidade de transcender o costumeiro e o universal. Acomodar-se às convenções estruturalistas é não permitir ampliar o pensamento e o discurso e assim, aceitar padrões limitantes.

Contemporâneo é aquele que mantém fixo o olhar no seu tempo, para nele perceber não as luzes, mas o escuro. Todos os tempos são, para quem deles experimenta contemporaneidade obscuros. Contemporâneo é, justamente, aquele que sabe ver essa obscuridade, que é capaz de escrever mergulhando a pena nas trevas do presente (AGAMBEN, 2013, p. 63).

Segundo o autor, essa falta de luz é a mesma de quando fechamos os olhos ou estamos no escuro, outras células começam a trabalhar na nossa retina, possibilitando a formação de outras imagens. Ou seja, perceber esse escuro não é uma forma de inércia ou passividade, mas uma habilidade de neutralizar outras luzes para descobrir as suas trevas. Desse modo, pode-se dizer que é contemporâneo aquele que não se deixa cegar pela claridade e, é aquele que percebe o escuro do seu tempo como algo que lhe concerne, aquele algo que se dirige diretamente a ele mais do que qualquer luz. Ser contemporâneo é uma raridade e um ato de coragem. Significa manter o olhar fixo no escuro e encontrar nele uma luz. É reconhecer nas trevas do presente, uma luz que nunca pode nos alcançar (AGAMBEN, 2013, p. 65).

O contemporâneo pode estar intimamente ligado à vida das imagens. Para Walter Benjamin, o índice histórico escrito nas imagens do passado mostra que elas alcançarão sua legibilidade somente num determinado momento da história e nós daremos ouvidos a esse acontecimento (AGAMBEN, 2013, p. 73). Da mesma forma que o contemporâneo percebe seu tempo, a imagem contemporânea também faz o mesmo e, por isso, está à altura de transformá-lo e colocá-lo em relação com outros tempos.

A vida das imagens contemporâneas e sua atuação como elemento contemporâneo depende da sua aparição nesse presente, da sua relação com o passado e das possibilidades que ela tem de agenciar

R. Inter. Interdisc. Art\&Sensorium, Curitiba, v.7, n.2, p. 015 - 027 Jul.- Dez. 2020 
ligações com o futuro. É um retorno e um salto que possibilita a atemporalidade, a relação e produção de sentidos em diferentes momentos, sem pertencimento a nenhum deles.

Evidentemente, o envolvimento com as imagens artísticas contemporâneas também é diferente. Todas as estruturas modernistas que definiam a arte, o belo, a figura do artista e o museu, foram corrompidas, para que a pluralidade, a heterogeneidade e a possibilidade tomasse conta da arte. $\mathrm{Ou}$ seja, produzir agora implica se adequar à essas condições pluralistas e, igualmente, todo o sistema acaba se refazendo.

Diante da infinidade de fazeres e saberes e, de todas as circunstâncias que atravessou, a naturezamorta cumpre um papel diferenciado na contemporaneidade e se mostra capaz de produzir discursos e significações antes imprensadas a partir da sua proliferação nas mais variadas formas. Uma análise estética da temática nos leva a entender que ela deixa de ser apenas uma representação do cotidiano, mas executa um papel conceitual em seus procedimentos. Isso quer dizer que, independente da forma, as mudanças mais significativas estão no conteúdo e o que querem dizer.

A singularidade da natureza-morta contemporânea não é só percebida pelas mudanças formais e estruturais da obra, mas por sua abordagem conceitual. Um gênero histórico que hoje é produzido sem o abrigo de uma narrativa histórica e linear. A incorporação de um tema tradicional, normalmente religioso, que hoje é apresentado em um contexto amplamente laico e híbrido. Ou seja, a conservação de algumas de suas formas as mantém sendo denominadas de natureza-morta, mas sua narrativa é totalmente revista, refeita e adaptada às problematizações contemporâneas.

Não quer dizer uma tradicional apreciação a fim de entender o que a imagem quer nos falar, mas a possibilidade de evocar conceitos que tornam possível entender o complexo mundo da experiência visual. Pensar em como as imagens são práticas culturais, propõem interpretações distintas e requisita diferentes perspectivas de olhar crítico, potencializando as imagens e a nossa capacidade de nos relacionarmos com elas e produzirmos nossas experiências.

As estratégias das naturezas-mortas contemporâneas, independentemente da técnica, ainda são caracterizadas pela conservação e persistência das formas silenciosas de seus objetos, de certo modo, padronizados. Contudo, ao contrário da inércia que parecia envolver as primeiras imagens a que temos contato - século XVI, hoje, elas adquirem uma dinâmica e uma força que expande as motivações do artista para além da representação de seu cotidiano, mas com uma presença marcada pelos questionamentos e problematizações referentes ao nosso contexto contemporâneo.

Portanto, levando em conta que apesar das mudanças de tempo e cultura, a natureza-morta ainda aparece atual, interessante e persistente. A persistência, derivada do latim persistere, significa "continuar com firmeza", per - "totalmente" e sistere - ficar firme, em pé. É sinônimo de estabilidade, firmeza, teimosia, perseverança. Persistência é esforçar-se para determinado objetivo, sem que as adversidades influenciem o contrário, sem que, no meio do caminho, as mudanças condicionem a outro foco.

Aqui, falamos de imagens que persistem. Falar que uma imagem persiste é afirmar que, mesmo diante de determinadas circunstâncias contrárias, que tentaram fazer sua vida desaparecer, a vida dessas imagens persistiu com força suficiente para continuar mobilizando e reaparecendo. Essa reaparição pode ser sutil ou pulsante, pode trazer de volta suas formas específicas e conhecidas, como também a potência de seus significados e suas preocupações relacionadas ao conteúdo. Sua persistência normalmente pode ser medida pela coincidência de formas e cores visíveis e enunciáveis que são familiares e que vêm de referências passadas.

A persistência dessas formas ocorre graças à troca e à soma de significados que vão adquirindo no decorrer da história. Em Diante do tempo (2015), Didi-Huberman, propõe um modelo de temporalidade para as imagens. Para ele, as imagens se relacionam porque a vida e a montagem se dão de forma heterogênea e descontínua, que se conectam através de um olhar contemporâneo, feito 
a partir de ressignificações do passado. Ou seja, é como se toda imagem contemporânea viesse de uma imagem do passado e ainda se conectasse com ela.

Quando falamos em sobrevivência, persistência, reaparição de formas ou imagens no campo da arte, remetemos, primeiramente, ao precursor do primeiro texto traduzido para língua portuguesa sobre o assunto: Geroges Didi-Huberman, com a publicação A imagem sobrevivente - História da arte e tempo dos fantasmas segundo Aby Warburg (2013). O autor desenvolve seu conceito de sobrevivência vindo do termo estrutura de recalque, esclarecendo como a história pode alcançar a contemporaneidade. Para ele, os elementos que retornam passam pelo recalque e revelam novamente estruturas antes já conhecidas, mas, algumas vezes, de outra forma.

No que diz respeito ao sentido de sobrevivência aqui tratado, entende-se como a ação e o efeito de sobreviver, é viver depois de um determinado acontecimento ou em condições adversas. Fazer sobreviver é a capacidade de manter vivo aquilo que foi suscetível ao desaparecimento, que cruzou por linhas extremas capazes de causar seu desaparecimento (DIDI-HUBERMAN, 2013, p. 110). Assegura que, quando olhamos para as imagens do passado, é importante percebermos como elas sobreviveram, cada vez que a observamos deveríamos pensar em todas as condições que impediram sua destruição. Um processo de imaginação e montagem: tentar fazer juntar fragmentos sobreviventes.

Para as imagens serem olhadas e interrogadas no presente, a história será entendida e interrogada pelas imagens antecedentes. Isso quer dizer que elas não são fáceis de entender, não são imediatas, mas estão no presente e, por isso, são capazes de produzir relações com esse tempo. Desse modo, em Quando as imagens tocam o real (2012), o mesmo autor interpreta a presença e a constância das imagens a partir do que chama de real, uma presença alcançada depois de estimulada. Ele retoma suas considerações sobre a potência das imagens enquanto produtoras culturais, com uma força que atravessa todas as civilizações, mais do que qualquer outro fator.

Para ele, a imagem não é só material visual, é impressão, rastro, traço do tempo que quis tocar. Antes mesmo de ser matéria, ela é imaginação, é ela quem forma e conduz nosso pensamento. Antigamente, já se falava que era difícil pensar sem imagens, hoje, Didi-Huberman (2013) fala que é impossível. Segundo o autor, nunca a imagem teve tanto alcance. Proliferou-se, dissolveu e ardeu tanto em seu contato com o real, por isso, ela também nunca tinha sofrido tanta censura. Por tocar o real, ela hoje expressa e expõe a civilização nas suas melhores e piores máscaras.

Com isso, coloca-se à prova a pertinência e a eloquência das imagens e da história, bem como o quanto sua vida persiste depois do momento de sua criação e sobrevive em outros tempos com problemas e interesses completamente diferentes. Outro subsídio teórico que lança esse olhar para as imagens é Imagem-Acontecimento, de Rosângela Cherem (2009). Baseada nos escritos de DidiHuberman, fala das imagens como evidências de um tempo dotadas de indícios singulares.

Para a autora, é preciso abandonar a noção de que a arte é somente produto do seu tempo e se delimita a um determinado lugar, é tempo de se pensar em imagens que se relacionam com recorrência e elementos recalcitrantes que retornam como vibrações sísmicas (CHEREM, 2009, p. 135). As imagens carregam suas épocas e encontros passados, mas também se interessam em repercutir no futuro.

É como se as mesmas imagens, ou a mesma combinação de elementos visuais, reaparecessem no tempo presente, problematizando as questões atuais e fomentando relações atemporais. Problematizar imagens artísticas já consagradas que retornam para contemporaneidade fora de seu tempo, possibilita a articulação de novas formas de criação e significação.

Esse reencontro dos elementos/imagens é um movimento que nunca volta idêntico, mas aparece como uma curva por onde espreitam outras constatações, igualmente pertinentes. Mais do que olhar por outros ângulos, é também uma mudança de posicionamento e de reconhecimento dessas imagens, um deslocamento de olhar que promove outras inquietações. É também a capacidade de 
interpretar um conjunto de coisas que cercam uma imagem e que já sofreram alterações: o contexto, por exemplo.

Segundo Cherem (2009), ao acrescentarmos outras iluminações a elas, reativando sua potência e as colocando em movimento novamente, reflete-se não mais sobre o que um dia foram ou o que produziram, mas sobre sua capacidade de continuar afetando e o que ainda podem dizer. É dar às imagens a oportunidade de ainda sobreviverem e discursarem no tempo presente, sobre as inquietações atuais.

Pelo viés da contemporaneidade múltipla e relativa, percebemos que esse possível agenciamento promove rupturas nas práticas universais da história da arte - feita sempre pelos mesmos enfoques e passa a operar segundo as variações da contemporaneidade e o encontro com novas imagens.

Considera-se então, a importância de repensar as imagens históricas não somente como registro deixado na história da arte, mas como legado que ainda pode repercutir. Reativá-las em justaposição às imagens contemporâneas e cotidianas pode produzir diferentes significados. Esse encontro promove uma ligação de formas que sobrevivem com antecipações e atrasos, com atualidades e inatualidades, um encontro de presença e aparições caracterizados por uma série de formas e componentes que complementam.

Portanto, entende-se que saber olhar uma imagem não se detém ao ato de contemplá-la por sua beleza ou memórias elucidadas. Saber olhar uma imagem é perceber onde ela arde, se faz pensar, se produz questionamentos, se cria sintomas e conhecimento (DIDI-HUBERMAN, 2012). Com isso, entende-se que perceber os sintomas facilitadores para as naturezas-mortas se proliferarem na contemporaneidade desconcerta o pensamento, renova a linguagem e o pensamento, faz com que a natureza-morta produza sentidos não só pelas problematizações atuais, mas pelas memórias que ela incita.

A contemporaneidade coloca a oportunidade de reativar e fazer persistir as imagens da naturezamorta da história da arte, faz com que o passado não pare de se reconfigurar a partir dessas fissuras, que permitem outras articulações antes impensadas. Um movimento de valorização do passado e de atualização, quando revisto na contemporaneidade a partir de outras formas e analogias. Um diálogo provedor de encaixes com as formas sobreviventes, valorizando a presença da naturezamorta na arte contemporânea.

\section{$O$ último que sair encoste a porta}

A proposta expositiva de $O$ último que sair encoste a porta faz referência aos conceitos expostos na primeira parte desse texto, referentes a persistência das naturezas-mortas na arte contemporânea e como elas se manifestam nesse tempo. O título dessa mostra rememora a fala do orientador do Ateliê de Pintura 1336, da Universidade Federal de Santa Maria - Rio Grande do Sul, Brasil, Alphonsus Benetti, este que pedia aos alunos do ateliê que encostassem a porta sempre que saíssem.

O Ateliê de Pintura 1336 da universidade existiu durante algumas décadas e reunia um grupo de pesquisadores/artistas que integravam o curso de Licenciatura ou Bacharelado em Artes Visuais, e desenvolviam seu trabalho em tinta óleo a partir de uma infinidade de temáticas particulares. Evidentemente, conforme passavam os anos, os integrantes iam mudando. Enquanto alguns se formavam, outros entravam no ateliê, onde cursavam pelo menos quatro semestres.

Com o passar do tempo, o vínculo entre as pessoas foi se estreitando e, por isso, era possível que independentemente de onde estivessem, continuavam frequentando o espaço do ateliê e colocando as conversas, o café e a arte em dia. Um ambiente mais do que de estudos, era também de amizades, de troca e de café, de segunda à sexta-feira às $10 \mathrm{~h}$ e às $16 \mathrm{~h}$, impreterivelmente e pontualmente. Durante os anos de funcionamento do ateliê, inúmeros foram os encontros fora da universidade e 
entre eles, várias propostas de exposições com intenção de divulgar o que os estudantes estavam produzindo, principalmente em pintura, naquele espaço.

No ano de 2017, o professor/orientador do ateliê, Alphonsus Benetti, também artista em Santa Maria/RS, se aposentou e, deixando de lecionar na universidade, o espaço do Ateliê 1336, também foi descaracterizado. Outro motivo para o ateliê perder sua configuração inicial foi a mudança do currículo e da estrutura do curso de Artes Visuais da universidade.

Depois desse acontecimento, surgiu a ideia de propor uma última exposição do grupo que estava recentemente no ateliê. A intenção foi revisitar aquele lugar através da pintura de naturezas-mortas com os objetos que integravam aquele espaço. Afinal, eram muitos os objetos característicos do ateliê que tornaram-se motivo de pesquisa para muitos estudantes.

As imagens daquele lugar carregavam histórias de amizade e momentos de aprendizado. Por isso, cada artista da exposição apresenta de forma muito peculiar suas memórias sobre aquele espaço, fazendo com que as imagens carreguem essas narrativas e percepções. A produção dessas imagens que aparecem por fragmentos, ou por completas, manifestam-se permitindo que esses objetos ganhem novos significados. Para os artistas, é evidente que, quando visualizarem algum desses objetos em outro local ou contexto, a memória ainda viva aparecerá, reafirmando o potencial da sobrevivência dessas formas que produziram significados mesmo com a passagem do tempo.

A contextualização dessas formas na contemporaneidade permite que os objetos ganhem outras dimensões que vão além da sua representação de forma naturalista. A imagem, inserida no cotidiano e no contexto de quem a produziu, como in: 1336 [Figura 1] de Antonio Junior, traz, além de uma composição de objetos a presença de elementos específicos que caracterizam essa obra dentro de um cenário contemporâneo.

Em primeiro plano, o nosso olhar atenta aos objetos principais da composição da cena, esses que eram conhecidos e importantes no Ateliê 1336. Em segundo plano e integrando a composição, o suporte de tecido em azulejaria portuguesa que traz elementos de uma outra vivência em outra cultura daquele artista. Esse caráter híbrido e nostálgico, afirma como a arte contemporânea pode migrar em diferentes linhas, agregando força e fazendo referência a diferentes elementos, capaz de produzir relações com o passado e com o presente.

Para pensar nessas imagens que compõe a mostra, foi analisado a importância e o papel dos objetos, a fim de compreender a relação do homem com estes artefatos que indiretamente são uma extensão da sua personalidade. Esse ponto de vista vai ao encontro do que Marcelo Rede propõe:

Pela sua própria materialidade, os objetos perpassam contextos culturais diversos e sucessivos, sofrendo reinserções que alteram sua biografia e fazem deles uma rica fonte de informação sobre a dinâmica da sociedade (transformações nos modos de relacionamento com o universo físico; mudanças nos sistemas de valores etc) (REDE, 1996, p. 276).

A representação dos objetos também carrega características e biografias, executam uma função e cumprem determinados papéis. Inclusive aqueles objetos efêmeros do ateliê, como as flores, frutas e o próprio cheiro de café, que remetem outros sentidos e associações que, por vezes, não estão tão presentes na memória. É evidente que o espaço do Ateliê de pintura 1336 foi um ambiente com muita vida, em que $O$ último que sair encoste a porta traduz, de diferentes maneiras, como aqueles objetos podem produzir sentidos em qualquer tempo e de qualquer forma.

Visto dessa maneira, confirma-se a ideia de que o objeto enquanto modelo nunca é passivo, estabelece relações, dialoga. No contexto do Ateliê de Pintura 1336, é afetivo. Os objetos que compõem as pinturas de naturezas-mortas que integram a mostra, têm, separadamente um sentido, 
uma origem e uma história. Confirmando-se assim, o poder expressivo e afetivo dos objetos que estão ao entorno.

Como afirma Baldessari, "A natureza-morta fala de coisas fugazes da vida. Cada objeto tem um significado simbólico ligado a ela. " (BALDESSARI, 2010, website). Essas imagens são um lugar alegoricamente pictórico, onde estão os objetos considerados, de algum modo, significativos. Como afirma Biagio D'Angelo, (2016, p. 150), “A natureza dos objetos é demostrada como ela o seria em seu significado imagético alegórico."

O Ateliê 1336, espaço de arte povoado por objetos, é o lugar das motivações poéticas. Seus objetos são impregnados pela rotina do ambiente, por isso, frequentemente são utilizados como referência. Dentre os muitos modelos para a observação que estavam dispostos para serem pintados, muitas vezes foram deixados de lado para que os objetos utilitários fizessem parte da composição. As garrafas e xícaras de café, por exemplo, eram usadas constantemente, por isso, pareciam impregnadas por aquele lugar e então, tornavam-se mais significativas. Como afirma Lima (2017, p. 6):

[...] o objeto, que se delimita e enquadra, e o modo como se delimita e enquadra constituem a expressão do próprio olhar, e evocam, pelo menos desde a 'emancipação' da natureza-morta, um quadro de motivações psicológicas e poéticas.

À estas peças, ou grupo de artefatos, Jean Baudrillard (1994, p. 81) designa o termo objetos marginais, estes: "parecem contradizer as exigências do cálculo funcional para responder a um propósito de outra ordem: testemunho, lembrança, nostalgia, evasão". A dissolução do ateliê em 2017, também conferiu a estes objetos tal status de memória e lembranças compartilhadas e afetivas. Um dos objetos com esse significado é a bocha, objeto de afeto do professor e artista Alphonsus Benetti, herdado por seu bisavô e parte integrante da pintura de Denise Losekann, sem título [Figura 2]. Outro exemplo é a manequim, denominada Tábata, trazida ao ateliê por um de seus egressos, e retratada na pintura Ave Tábata, rogai por nós os pintores de Marco Gomes [Figura 3].

Estes objetos utilitários, trazidos pelos discentes, como a Tábata, se tornaram motivo de interesse para a produção pictórica de muitos integrantes. Assim como as utilidades do café. Desde as térmicas que o armazenavam até as tradicionais bolachas. Cada aluno tinha sua xícara, que permanecia parte do acervo do ateliê. Incorporados à dinâmica daquele espaço, bustos, cadeiras, xícaras e garrafas adquiriam ali sua razão de ser. Como na pintura de Antonio Junior, onde destaca sua xícara azul, na obra in: 1336, mencionada anteriormente.

A proposta de $O$ último que sair encoste a porta oportunizou que o ateliê permanecesse eternizado. Durante o ano de 2019 a exposição que se tornou itinerante, aconteceu em dois espaços: Sala de Exposições Nelson Ellwanger no município de Silveira Martins/RS e no Espaço Arte 8 UNIVATES na cidade de Lajeado/RS. E, nesses dois momentos, os artistas e ex-integrantes do ateliê tiveram a oportunidade de se encontrar e compartilhar a experiência de visualizar, novamente, o antigo Ateliê 1336, só que em pinturas.

Esse momento de partilha reuniu memórias e histórias antes nunca comentadas. A passagem do tempo até chegar nesse encontro trouxe os artistas de vários lugares, cada um seguindo seu rumo e criando sua trajetória no campo artístico. Diante da exposição montada, a energia daquele lugar contaminou todos que estavam na sua versissage. De fato, ao mesmo tempo que se via todas as pessoas em suas respectivas pinturas, também parecia que todos os artistas tinham participado de todas as pinturas. Essa sensação confirmou o quanto as imagens têm força e carregam um poder que desconcerta o pensamento. Foi uma oportunidade de ver o Ateliê 1336 novamente, de ver seus integrantes e reviver todos aqueles momentos, apenas diante de tanta tinta a óleo. 
As imagens de objetos significativos "[...] se caracteriza, então, como fluxo e, para além de suas dimensões espaciais adquire, também, aspectos temporais. [...] se caracteriza pelo fluxo de tempo e de pessoas, trânsito e a troca com o outro. [...]" (SILVA, 2001 p. 72). As trocas, as vivências e as experiências também são parte dessas pinturas, ainda que não sejam retratadas visualmente. Os objetos e a massa de tinta dessas naturezas-mortas tornam-se interlocutores das experiências compartilhadas naquele espaço, permitindo a sobrevivência do Ateliê 1336, sua reaparição e manifestação coexistente em diferentes tempos. O último que sair encoste a porta foi, de fato, um último olhar ao ateliê, um último encontro que permitiu partilhas especiais. E agora, através daquelas pinturas, pode-se dizer que ele ainda existe e suas imagens vão coexistir independente do tempo.

\section{Considerações finais}

A partir das considerações feitas sobre a temática da natureza-morta e sua adaptação na contemporaneidade, percebe-se que, independentemente do tempo em que foram criadas e do contexto histórico a que pertenciam, as naturezas-mortas ainda são uma questão na produção dos artistas contemporâneos. Mesmo pertencendo a uma história exclusivista, europeia e canônica, a temática consegue ultrapassar todas essas limitações históricas para se mostrar e reaparecer num contexto totalmente conceitual e múltiplo.

Valorizar as imagens, reativá-las e traze-las para a arte contemporânea, é dar às imagens a oportunidade de se mostrarem novamente, mas com outros objetivos. Reconhecer que as formas têm força para sobreviver e sofrerem as mutações necessárias para que se mostrem pertinentes nos dias que correm, é entender que a arte se mantém independente dos contratempos e de todos os recursos que tentaram a diminuir.

A persistência das imagens de naturezas-mortas na arte contemporânea confirma que, mesmo fazendo referência a um gênero silencioso e inerte, hoje elas podem se manifestar de forma provocativa e contestadora. Também é possível estabeleceram relações com uma série de artefatos que não dizem respeito somente a arte, mas ao contexto, aos problemas e as experiências que atravessam o momento de criação dessas imagens. A contemporaneidade permite a articulação de inúmeras referências, conceitos, ideias, materiais, enfim, é uma oportunidade para potencializar imagens que ainda parecem adormecidas.

A força que a natureza-morta alcança e as questões que ela implica na contemporaneidade podem ser visualizadas na exposição $O$ último que sair encoste a porta. Ela traduz como o passado e a memória fazem repercutir novas ideias no presente. É um diálogo entre os tempos, que traz elementos sobreviventes, mas também possibilidades futuras, tornando possível uma relação atemporal com diferentes sintomas e vibrações.

A oportunidade de reviver o espaço do Ateliê 1336, foi de grande importância para os artistas. Alguns que tiveram que interromper suas produções quando o espaço foi desativado, foram novamente agraciados pela oportunidade da pintura; enquanto outros, que há muito tempo estavam distantes, tiveram de voltar às suas memórias, experiências e pincéis.

Evidentemente, a natureza-morta foi o tema mais pertinente para ser revisitado, e que ligava, de igual forma, todos os artistas. O novo olhar para os antigos objetos nas pinturas, produziu não só novas lembranças, mas novas imagens a partir do que um dia já foram. Tudo isso traduziu, de forma literal, o quanto as imagens podem reaparecer na arte pela insistência de suas características sobreviventes, fazendo ser possível criar outras imagens e uma série de significados que são atualizados, reinterpretados e compartilhados. 


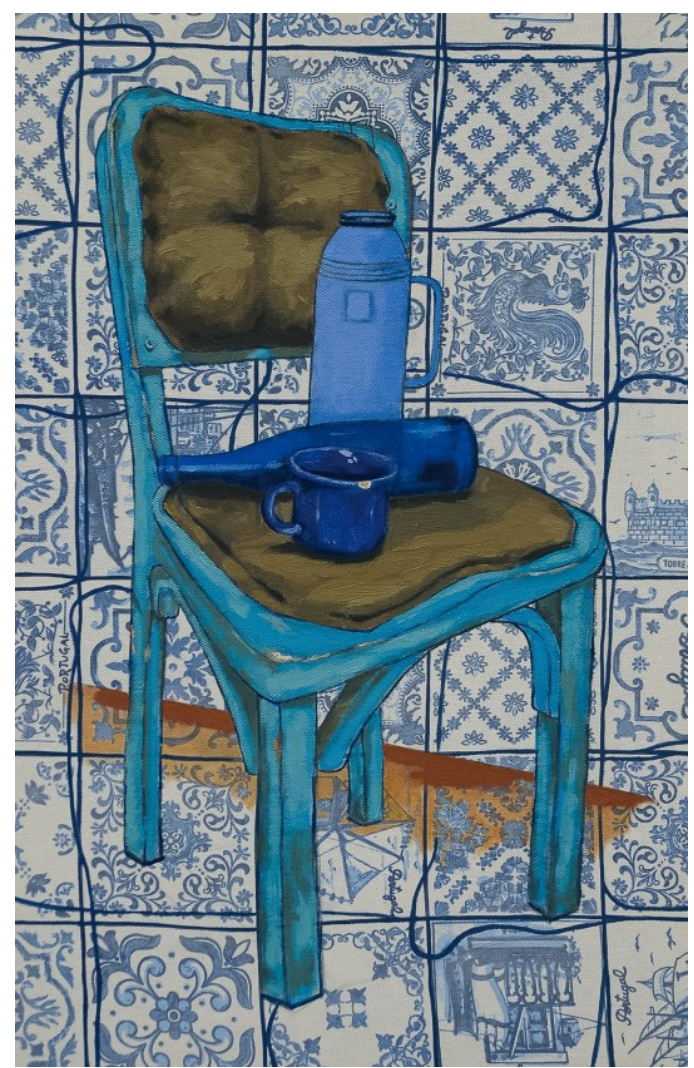

Figura 1: Antonio Junior, in: 1336, 2017, Óleo sobre tela, $64 \mathrm{~cm} \mathrm{x} 42 \mathrm{~cm}$.

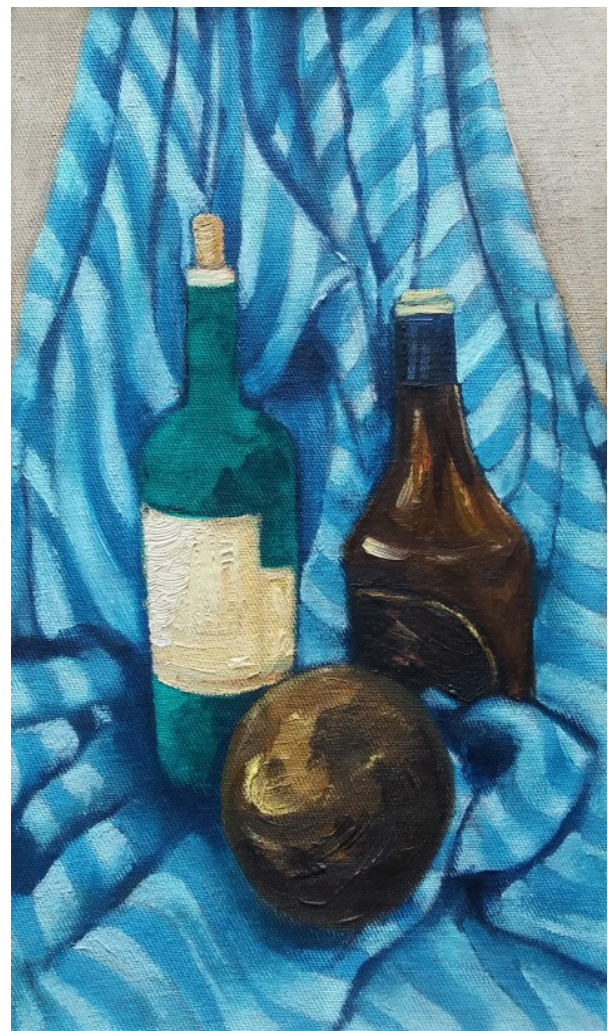

Figura 2: Denise Losekann, Sem título, Óleo sobre tela, 2016, $56 \mathrm{~cm} \mathrm{X} \mathrm{38cm.}$

R. Inter. Interdisc. Art\&Sensorium, Curitiba, v.7, n.2, p. 015 - 027 Jul.- Dez. 2020 


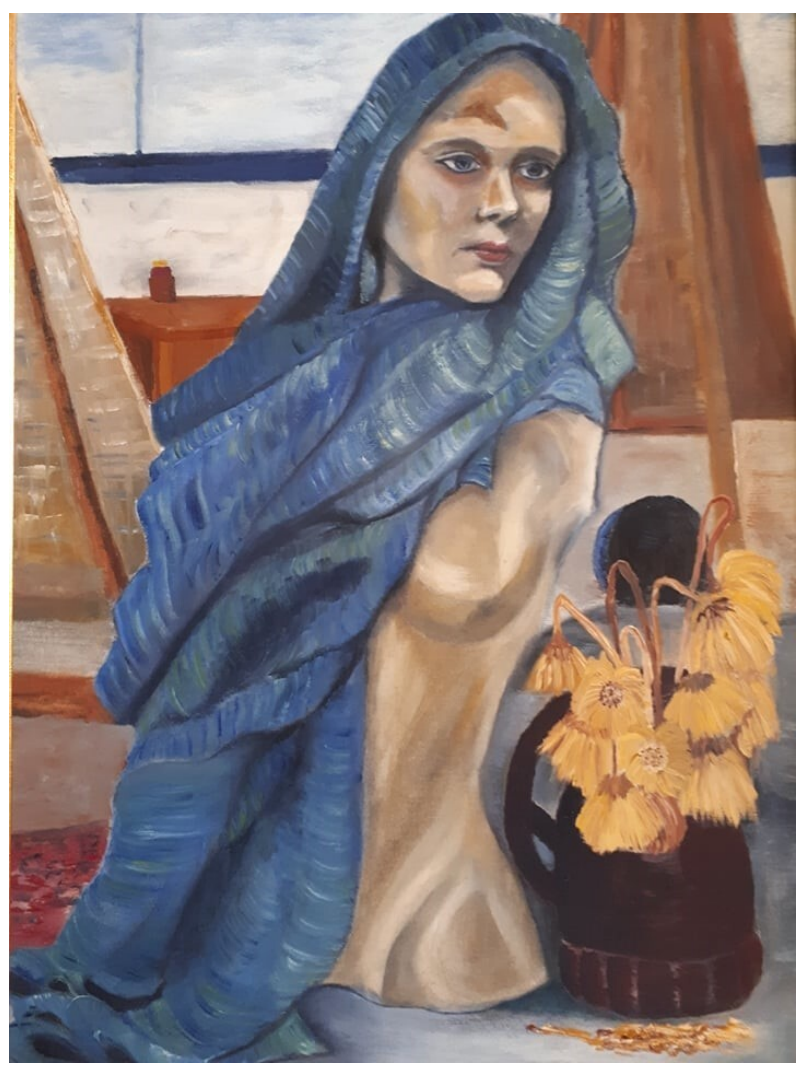

Figura 3: Marco Gomes, Ave Tábata: Rogai por nós os pintores, Óleo sobre tela, $201656 \mathrm{~cm} \mathrm{X} \mathrm{40cm.}$

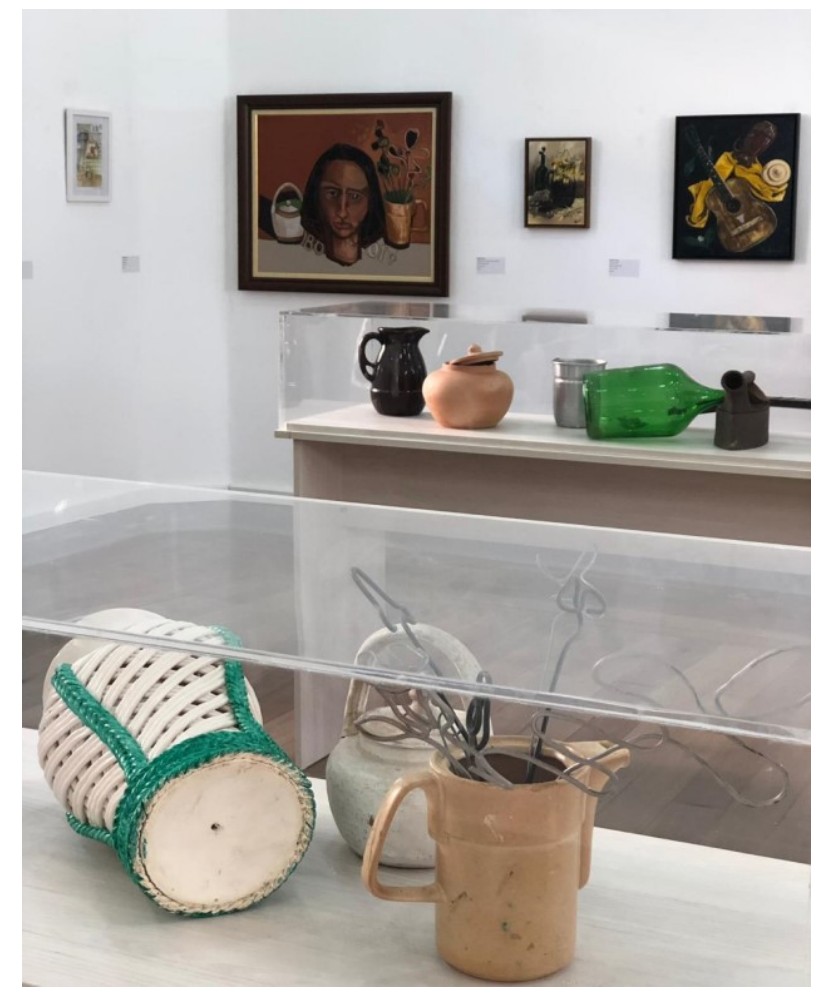

Figura 4: Registro da exposição em Silveira Martins/RS. Vernissage: 02 de agosto de 2019. Foto de Milena Duarte Corrêa. 


\section{Referências}

AGAMBEN, Giorgio. O que é o contemporâneo e outros ensaios. Chapecó: Argos, 2013.

BALDESSARI, John. In Still Life. Disponível em <http://www.rawfunction.com/in-still-life-johnbaldessari> Acesso em: 22 mai. 2019.

BAUDRILLARD, Jean. O sistema dos Objetos. Tradução: Zulmira Ribeiro Tavares. São Paulo: Perspectiva, 1994.

BAUMAN, Zygmunt. Legisladores e Intérpretes: sobre modernidade, pós-modernidade e intelectuais. RJ: Zahar, 2010.

CHEREM, Rosângela Miranda. Imagem - acontecimento. In: Linhas cruzadas: artes visuais em debate / organização: Maria Cristina da Rosa Fonseca da Silva, Sandra Makowiecky Florianópolis: Editora UDESC, 2009.

D’ANGELO, Biagio. Tecnologia da visão: as naturezas-mortas de Sam Taylor Wood, Ori Gersht e John Baldessari. Mutações, confluências e experimentações na arte e tecnologia. Brasília: Editora PPG Arte/UnB, p. 25-34, 2016.

DIDI-HUBERMAN, Georges. A imagem sobrevivente: história da arte e tempo dos fantasmas segundo Aby Warburg. Trad. Vera Ribeiro. Rio de Janeiro: Contraponto, 2013.

. Diante do tempo: história da arte e anacronismo das imagens. Tradução de Vera Casa Novas e Márcia Arbex. Belo Horizonte: Editora UFMG, 2015.

Quando as imagens tocam o real. PÓS: Revista do Programa de Pósgraduação em Artes da EBA/UFMG, vol. 2, n. 4, p. 204-219, 30 nov. 2012.

LIMA, Luís Carlos Fortunato. "Naturezas-Mortas" Antes da Natureza-Morta: Bases para o Estudo e Contemplação das Formas Preliminares da Natureza-Morta em Portugal. Tese de doutorado em Arte e Design - Faculdade de Belas Artes da Universidade do Porto. Porto, 2017. Disponível em: $<$ https://hdl.handle.net/10216/104099. > Acesso em: 28 mai. 2019.

REDE, Marcelo. História a partir das coisas: tendências recentes nos estudos de cultura material. Anais do Museu Paulista: História e Cultura Material, v. 4, n. 1, p. 265-282, 1 jan. 1996.

SILVA, Fernanda Pequeno da. Ateliês Contemporâneos: possibilidades e problematizações. Anais do $56^{\circ}$ Encontro da Associação Nacional de Pesquisadores em Artes Plásticas, Rio de Janeiro, p. 59-73. Disponível em:

$<$ http://www.anpap.org.br/anais/2011/pdf/cc/fernanda_pequeno_da_silva.pdf.> Acesso em: 23 mai. 2019. 